\title{
COVID-19 symptoms-does pregnancy alter the course of the disease
}

\author{
Sabnam S. Nambiar*, Reshmi V. P., Ajith S.
}

Department of Obstetrics and Gynaecology, Government Medical College, Kannur, Kerala, India

Received: 27 September 2020

Accepted: 05 November 2020

\section{*Correspondence:}

Dr. Sabnam S. Nambiar,

E-mail: sabnamsn@rediffmail.com

Copyright: ( ) the author(s), publisher and licensee Medip Academy. This is an open-access article distributed under the terms of the Creative Commons Attribution Non-Commercial License, which permits unrestricted non-commercial use, distribution, and reproduction in any medium, provided the original work is properly cited.

\section{ABSTRACT}

Background: COVID-19 or corona virus 2 is a widespread pandemic taking a huge toll on the world population.it has a varied presentation in different age groups. Similarly, it has a poorer outcome in the elderly with various comorbidities and those who are immunocompromised. Though pregnancy is a relatively immunocompromised state studies have found that pregnant women have a less severe presentation. We have tried to assess this aspect of COVID-19 in pregnant women.

Methods: We evaluated the records of 158 pregnant women who presented to our hospital from April 2020 till September 2020. Their symptoms at presentation were evaluated. we also noted the outcome of these pregnancies.

Results: $16 \%$ of these were more than 34 weeks of period of gestation. $65.19 \%$ presented without any symptoms. $15.19 \%$ presented with fever. $10.75 \%$ presented with cough. $8.22 \%$ presented with headache. $5.69 \%$ presented with sore throat alone. $3.16 \%$ presented with breathlessness. $0.63 \%$ presented with anosmia alone, loss of taste, severe acute respiratory infection, vomiting, sore throat and breathlessness respectively. 54 patients delivered of which 7 delivered vaginally and there were 47 caesareans. Remaining patients after cure were discharged. There were 3 miscarriages. Two babies were found to be COVID-19 positive from nasopharyngeal swab taken on day 1 , however this was a small number to indicate vertical transmission.

Conclusion: Our study showed that a large proportion of pregnant patients presented without symptoms.it remains to be evaluated why this is so.it may provide us with clues on how to deal with disease in the general population.

Keywords: COVID-19, Pregnancy, Fever, Symptoms, Cough, Sore throat, Anosmia, Diarrhoea

\section{INTRODUCTION}

COVID 19 (Corona virus 2) which originated in Wuhan, China has been found to be an extremely infectious malady which spread around the world in no time and took the form of a fearsome pandemic. ${ }^{1,2}$ Around 32.8 million cases have been reported worldwide with over 994,000 deaths. ${ }^{3}$ It presents with fever, cough, fatigue, shortness of breath, dyspnoea, anosmia, loss of taste, diarrhoea. some present with mild symptoms, while some develop acute respiratory distress syndrome (result of cytokine storm), multiorgan failure, septic shock and thromboembolism. $^{4,5}$ It has an incubation period of around two to fourteen days, spread mainly through droplet spread by way of talking, sneezing or coughing. ${ }^{6}$ It may also spread from contaminated surfaces .The diagnosis is done by real time reverse transcription polymerase chain reaction (rt-pcr) from a nasopharyngeal or oropharyngeal swab. ${ }^{7}$ Chest CT can also help in diagnosis. ${ }^{8,9}$ Pregnancy is a state of relative immunosuppression. Hence theoretically speaking based on available data on SARS and MERS pregnant women are at a higher risk of severe infection requiring intensive care. ${ }^{10,11,12}$ However SARS-CoV and SARS-CoV2 appear to have less severe symptoms with few studies showing vertical transmission in children born to mothers with the disease. $^{13}$ 
In pregnancy the immune system is altered with suppression of cell mediated immunity and predominance of humoral immunity. This may affect the ability of the pregnant women to fight the virus. In addition, the physiological changes of pregnancy also put a load on the cardiovascular status and the lungs. These factors may increase the risk of COVID-19 in pregnancy and also threaten a more sinister presentation. The virus affects the lungs using angiotensin converting enzyme 2 (ACE2), found significantly in the alveolar cells of the lungs. ${ }^{14,15}$ The virus has a surface glycoprotein or spike protein which connects to ACE2 to enter the cell. ${ }^{16}$ Thus it is postulated that reduction in ACE2 activity might be protective. ${ }^{16}$

However, the severity of the disease is found to be aggravated by virus induced deficiency of ACE2 as seen in elderly and diseased persons. This increases dysregulation between adverse ACE-angiotensin II-AT1 receptor axis and the protective ACE2-angiotensin 1-7Mas receptor axis. This might cause progressive inflammatory and thrombotic processes triggered by local angiotensin II hyperactivity unopposed by angiotensin 17in the lungs. ${ }^{17}$

ACE2 is deficient in pregnancy. ${ }^{18}$ The virus induced additional ACE2 deficiency may aggravate the damage.

Some studies have however shown that pregnant women presenting with less severe symptoms compared to nonpregnant individuals. ${ }^{19} \mathrm{We}$ have tried to examine this aspect of COVID-19 by observing the presentation and course of the disease in a retrospective study of 158 women admitted to our institution.

\section{METHODS}

The study was retrospective study carried out at government medical college, Kannur, Kerala (a tertiary referral hospital and medical college). During period of April to September 2020

Selection criteria for the study was all pregnant women diagnosed with COVID-19 in our institution or referred to our institution with a COVID positive report. all such women were admitted for management.

We collected the data of 158 women admitted and treated in our institution from April till September 2020, retrospectively. We observed the age, the parity, comorbidities in these women. Then we examined as to how these women had presented with, when diagnosed as COVID positive. The women were diagnosed with the help of RT PCR/rapid antigen test and discharged once Rapid antigen test was found to be negative. Those remote from term were discharged after a ultrasonogram done to confirm foetal wellbeing once diagnosed as COVID 19 negative.
The characteristics observed were maternal age, period of gestation, presence of other comorbidities like hypertension, diabetes, hypothyroidism, seizure disorder, bronchial asthma. Symptoms observed were documented. Outcome of the pregnancies have also been documented.

All the data was taken retrospectively from the patient records. Patient confidentiality has been strictly maintained. Approval was taken from the institutional ethical committee. Data was entered in Microsoft excel sheet and analysed with appropriate statistical software.

\section{RESULTS}

\section{Patient characteristics}

$96.20 \%$ women were less than 35 years, and $3.79 \%$ were more than or equal to 35 years.

Table 1: Age distribution.

\begin{tabular}{|lll|}
\hline Age (year) & No. of patients & Percentage (\%) \\
\hline $\mathbf{3 3 5}$ & 152 & 96.20 \\
\hline $\mathbf{3 5}$ & 6 & 3.79 \\
\hline
\end{tabular}

$34.81 \%$ women were primiparas and $65.19 \%$ were multigravida.

Table 2: Parity.

\begin{tabular}{|lll|}
\hline Parity & No. of patients & Percentage (\%) \\
\hline Primi & 55 & 34.81 \\
\hline Multi & 103 & 65.19 \\
\hline
\end{tabular}

$53.16 \%$ women had presented after 34 weeks of gestation.

Table 3: Period of gestation at presentation.

\begin{tabular}{|lll|}
$\begin{array}{l}\text { Period of gestation } \\
\text { (Weeks) }\end{array}$ & $\begin{array}{l}\text { No. of } \\
\text { patients }\end{array}$ & Percentage $(\%)$ \\
\hline $\mathbf{2 8}$ & 42 & 26.58 \\
\hline $\mathbf{2 8 - 3 4}$ & 32 & 20.25 \\
\hline $\mathbf{3 4}$ & 84 & 53.16 \\
\hline
\end{tabular}

\section{Symptoms and signs}

Though all these women were admitted with a COVID positive report, $68.35 \%$ were found to be asymptomatic. These women were diagnosed to be positive chiefly due to history of contact with positive family members or due to history of travel from high risk areas.

$15.19 \%$ presented with fever. $10.75 \%$ presented with cough. $8.22 \%$ presented with headache associated with other symptoms like fever, sore throat etc. $5.69 \%$ presented with sore throat alone. $3.16 \%$ presented with breathlessness. $2.53 \%$ presented with rhinitis. $2.53 \%$ presented with anosmia in association with other 
symptoms, $0.63 \%$ presented with anosmia alone. $1.89 \%$ presented with headache alone. $1.89 \%$ presented with diarrhoea. $1.89 \%$ presented with fatigue. $0.63 \%$ presented with vomiting. $0.63 \%$ presented with sore throat and breathlessness.

1 patient $(0.63 \%)$ 26-year-old primi presented at 27 weeks with complaints of cough, breathlessness, and oxygen saturation of $90 \%$.she was admitted to ICU and treated with ceftriaxone, oseltamivir, dexamethasone, azithromycin and hydroxychloroquine.

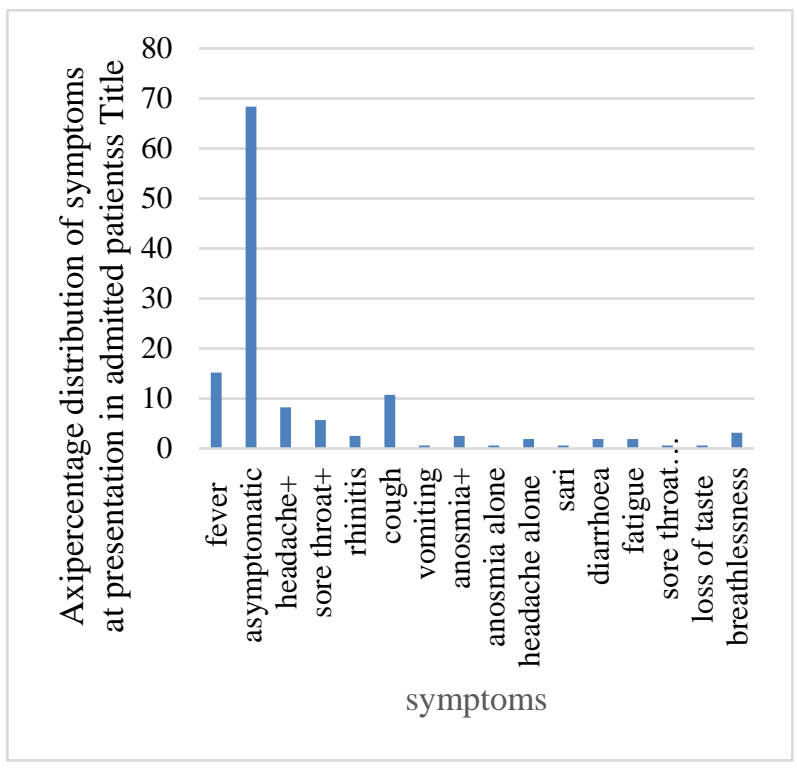

Figure 1: Axipercentage distribution of symptoms at presentation.

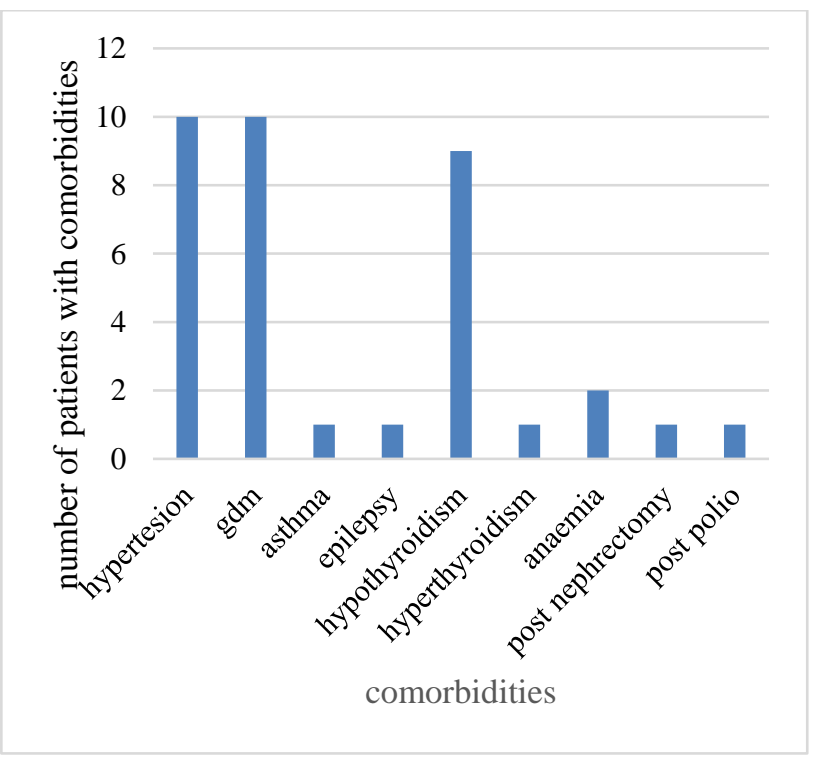

Figure 2: Number of patients with comorbidities.

There were 54 patients who delivered.7 delivered vaginally between $38-40$ weeks, with spontaneous onset of labour of the 35 emergency caesareans 10 were in women with comorbidities like hypertension and diabetes.

In our study there were 10 women with hypertension of which 7 underwent emergency caesarean section due to fetal distress, meconium stained amniotic fluid. 2 had severe intrauterine growth restriction. It is difficult to assess however whether this outcome was a result of preeclampsia primarily or secondary to COVID-19.

Among the 10 patients with gestational diabetes mellitus 2 developed foetal distress, one developed prom and foetal distress necessitating emergency caesarean section. One of the patients also presented with breathlessness.

One patient suffering from post-polio residual paralysis presented at 9 weeks with COVID positive status. she subsequently suffered from miscarriage. 2 more patients suffered miscarriage one at 10 weeks and another 15 weeks.

There were 47 caesarean sections of which 33 were primary and 14 were cases of repeat caesarean sections. There were 10 emergencies preterm and 25 term emergency caesarean sections due to reasons ranging from foetal distress to abnormal doppler parameters.

\section{DISCUSSION}

COVID-19 has emerged as an epidemic of unparalleled proportions. It has killed millions in its wake and left many with damaged lungs and other comorbidities. As mentioned earlier, the pregnancy specific physiological changes leave the pregnant women all the more vulnerable to COVID-19. However various studies have shown that pregnant women are less likely to present with severe form of COVID.

A systematic review and metanalysis published in British Medical Journal in September 2020 by Allottey et al, compared 77 studies done worldwide, showed that pregnant women were less likely to present with symptoms like fever and myalgia. ${ }^{19}$ However in those with severe infection, they were more likely to require intensive care. Pregnancies affected with pre-existing conditions such as hypertension, diabetes or obese women are more likely to have more severe complications due to COVID. The findings of our study also correlated with the same. In our study we also found that around $68.35 \%$ presented without any symptoms and only $15.19 \%$ presented with fever. This study also showed lower incidence of fever, cough and dyspnoea.

The caesarean section rate was $87 \%$ which is quite significant.

According to Chen et al, pregnant patients did not have a severe presentation, none had a disease predating pregnancy between 27-40 years of age. ${ }^{20}$ The most significant symptoms were fever $(78 \%)$, postpartum fever 
(68\%), myalgia (33\%) malaise (22\%) cough (44\%). There was one case of preeclampsia and one case of abnormal liver function.

10 patients had hypertensive disorder of pregnancy of which 8 presented with severe preeclampsia. Mendoza et al have referred to occurrence of a preeclampsia like syndrome induced by COVID-19, which may however be distinguished by Sflt-1/PIGF, LDH (lactate dehydrogenase) and UtAPI (uterine artery pulsatility index) assessment. ${ }^{21}$ However in our study only LDH was found to be raised, the other tests could not be done due to logistical difficulties due to patient load and economic non feasibility. Hence, we cannot be sure whether it was true preeclampsia.

Our study found only $15 \%$ cases of fever at presentation, with more than $60 \%$ presenting without any symptoms, detected only due to history of travel or contact with high risk persons. The course of the disease has been found to be milder in pregnant women in most case series from across the globe. Pregnancy is a condition with decreased cell mediated immunity, hence there are fears of the disease worsening. However, studies have also shown a reduced concentration of Angiotensin converting enzyme levels in pregnancy. Consequently, this could correlate with reduced ACE receptor expression on cells as ACE receptors are found to be the primary site where virus binds to the cell. This could be the probable cause for the milder presentation in pregnancy. However there have been some reports especially from some Chinese studies stating the probable increase in abnormal foetal heart rate patterns, foetal distress, miscarriages and adverse obstetric outcome. ${ }^{21}$

\section{Limitations}

The chief limitation of the study was that as data was taken retrospectively, so no active intervention could be done. The treatment protocol could also not be standardised due to the same reason. The fact that there is no adequate data available on COVID positive pregnancies to help guide treatment protocols was also a limitation.

\section{CONCLUSION}

Our study showed that majority of pregnant patients had presented asymptomatically. Though 5 patients presented with breathlessness, only one presented with severe acute respiratory infection. Only $15 \%$ presented with fever. Hence it is very important to test all pregnant women with COVID-19 RT PCR especially considering the present scenario of increasing spread of the disease. Though we found that most patients in our series have been largely asymptomatic, however there is a possibility of a very sinister presentation in pregnancy, which can be life threatening. Larger studies may provide us with a clearer and possibly varied picture. One reason for such an outcome because of the possible difference in patient attitudes in this part of the country. Here there were patients who had read about anosmia and presented for check-up because of the same.

Hence it is imperative that information of symptoms and risk factors be disseminated widely.

It must be further evaluated as to why the disease is presenting chiefly asymptomatically in pregnant women, in spite of the altered immune status in pregnancy. It could even provide us insights for probable targets of vaccine or development of cure for COVID-19.

Funding: No funding sources

Conflict of interest: None declared

Ethical approval: The study was approved by the Institutional Ethics Committee

\section{REFERENCES}

1. Hui DS, Azhar E, Madani TA, Ntoumi, Kock R, Dar $\mathrm{O}$, et al. The continuing 2019-nCoV epidemic threat of novel coronaviruses to global health: the latest 2019 novel coronavirus outbreak in Wuhan China. Int J Infect Dis. 2020;91:264-6.

2. WHO Director general's opening remarks at the media briefing on covid 19 . World health organization press release. Available at: https://www.who.int/director-

general/speeches/detail/who-director-general-sopening-remarks-at-the-mission-briefing-on-covid19---12-march-2020. Accessed on 12 March 2020.

3. COVID-19 dashboard by the centre for systems science and engineering (CSSE) at johns Hopkins. Available at: https://github.com/CSSEGISandData/ COVID-19. Accessed on 12 March 2020.

4. Symptoms of corona virus. U S Centre for disease control and prevention (CDC). Available at: https://www.cdc.gov/coronavirus/2019.

ncov/symptoms-testing/symptoms.html. Accessed on 14 April 2020.

5. Q and A on corona virus (COVID-19). World health organization archived from the original. Available at: https://www.who.int/dg/speeches/detail/whodirector-general-s-opening-remarks-at-the-mediabriefing-on-covid-19---11-march-2020. Accessed on 11 March 2020.

6. Q and A on coronaviruses. World health organization (who) archived from the original on 20 Jan 2020. Available at: https://www.who.int/newsroom/detail/27-04-2020-who-timeline---covid-19. Accessed on 16 April 2020.

7. European Centre for Disease Prevention and Control. $\mathrm{Q}$ and $\mathrm{A}$ on COVID-19. Available at: https://www.who.int/reproductivehealth/publications /emergencies/COVID-19-SRH/en/. Accessed on 30 April 2020.

8. Salehi S, Abedi A, Balakrishnan S, Gholamrezanezhad A. Coronavirus disease 2019 
(COVID-19): a systematic review of imaging findings in 919 patients. Am J Roentgenol. 2020:1-7.

9. American College of Radiology. ACR recommendations for the use of chest radiography and computed tomography (CT) for suspected COVID-19 infection. ACR website. Available at: dvocacy-and Economics/ACR-PositionStatements/Recommenda tions-for-ChestRadiography-and-CTfor-Suspected-COVID19Infection. Accessed on 11 March 2020.

10. Omrani AS, Saad MM, Baig K, Bahloul A, AbdulMatin M, Alaidaroos AY. Ribavirin and interferon alfa-2a for severe middle east respiratory syndrome coronavirus infection: a retrospective cohort study. Lancet Infect Dis. 2014;14(11):1090-95.

11. Payne DC, Iblan I, Alqasrawi S, Nsour MA, Rha B, Tohme RA. Stillbirth during infection with middle east respiratory syndrome coronavirus. J Infect Dis. 2014;209:1870-72.

12. Malik A, El Masry KM, Ravi M, Sayed F. Middle east respiratory syndrome coronavirus during pregnancy, Abu Dhabi, United Arab Emirates. Emer Iinfect Dis. 2013;2016(22):515-7.

13. Vasylyeva O. Pregnancy and COVID-19, a brief review. Int $\mathbf{J}$ Integr Pediatr Environ Med. 2020;5(1):8-13.

14. Ge XY, Li JL, Yang XL, Chmura AA, Zhu G, Epstein JH. Isolation and characterization of a bat SARS-like coronavirus that uses the ace 2 receptor. Nature. 2013;503(7477):535-8.

15. Letko M, Marzi A, Munster V. Functional assessment of cell entry and receptor usage for SARS-CoV-2 and other lineage $B$ beta corona viruses. Nature Microbiol. 2020;5(4):562-9.
16. Zhang H, Penninger JM, Li Y, Zhong N, Slutsky AS. Angiotensin-converting enzyme 2 (ACE2) as a SARS-CoV-2 receptor: molecular mechanisms and potential therapeutic target. Intens Care Med. 2020;46(4):586-90.

17. Xu H, Zhong L, Deng J, Peng J, Dan H, Zeng X et al. High expression of ACE2 receptor of 2019-nCoV on the epithelial cells of oral mucosa. Inter $\mathrm{J}$ Oral Sci. 2020;12(1):8.

18. Verdecchia P, Cavallini C, Angeli F. The pivotal link between ACE2 deficiency and SARS-COV2 infection. Eur J Intern Med. 2020.

19. Allotey J, Stallings E, Bonet M, Yap M, Chatterjee $\mathrm{S}$, Kew $\mathrm{T}$, et al. Clinical manifestations, risk factors, and maternal and perinatal outcomes of coronavirus disease 2019 in pregnancy: living systematic review and meta-analysis. Brit Med J. 2020;370.

20. Chen H, Guo J, Wang C. Clinical characteristics and intrauterine vertical transmission potential of COVID-19 infection in nine pregnant women: a retrospective review of medical records. Lancet. $2020 ; 805$.

21. Irani $\mathrm{R}$, Xia $\mathrm{Y}$. Renin angiotensin signalling in normal pregnancy and preeclampsia. Semin Nephrol. 2011;31(1):47-58.

Cite this article as: Nambiar SS, Reshmi VP, Ajith S. COVID-19 symptoms-does pregnancy alter the course of the disease. Int J Reprod Contracept Obstet Gynecol 2020;9:5032-6. 